\title{
Evaluation of fluorinated hydroxyapatite nanoparticles as an antibacterial material for catheter coating
}

\author{
Hiroki Gyotoku', Yoshinano Azuma ${ }^{2}$ and Tsutomu Furuzono ${ }^{1 *}$ [D
}

\begin{abstract}
Background: Catheter-related infection of peritoneal dialysis (PD) is one of the serious factors of peritonitis. However, an antibacterial PD catheter has not been commercially available in Japan yet. From an infection control viewpoint, it is necessary to develop an antibacterial coating material for catheters with a long-term effectiveness.

Methods: Fluorinated hydroxyapatite (F-HAp) nanoparticles were prepared by a wet chemical process. F-HAps with different $\mathrm{F}$ substitution contents were prepared by adjusting the feed ratio of $\mathrm{F}$ ions versus sites of $\mathrm{OH}$ groups in HAp structures. The characterization and evaluation of F-HAps were conducted using several analytical equipment and an antibacterial powder assay.

Results: The F-HAp nanoparticles possessed highly crystalline and dispersibility. The F-HAps were named as F(30)HAp, F(50)-HAp, and F(100)-HAp and were 24, 52, and 84\% of the actual F substitution content, respectively. The nanomaterials showed acidic resistance, i.e., chemical stability, compared to normal HAp. In an antibacterial assay of $\mathrm{F}(100)$-HAp with $50 \mathrm{mg}$ in $0.2 \mathrm{~mL}$ of $\mathrm{NaCl}$ aqueous solution, four types of causative bacteria of catheter-related infections, Pseudomonas aeruginosa, Staphylococcus aureus, Enterobacter aerogenes, and Klebsiella pneumoniae were used. The antibacterial activities of F(100)-HAp showed 50-60\% against the microorganisms. F ions were gradually released and finally plateaued at 24 weeks.

Conclusions: The retention possibility of the antibacterial effect of F(100)-HAp potentially lasted for 24 weeks based on the $\mathrm{F}$ ions release behavior. It is expected that the antibacterial performance can be improved by the precise control of material engineering technology, although the duration of the effect has not yet been satisfactory for a PD catheter.
\end{abstract}

Keywords: Peritoneal dialysis, Fluorinated hydroxyapatite, Dispersibility, Antibacterial activity

\section{Background}

During peritoneal dialysis (PD), peritonitis is one of the most serious complications that often occur [1]. One cause of this complication may be catheter infection. Exit-site infection (ESI) and tunnel infection are also well-known risk factors [2]. P. aeruginosa and S. aureus are cited as causative bacteria of these infections [3]. In addition, former studies using conventional silicone catheters suggest that silver ion-coated catheters could minimize bacteria colonization and reduce the rate of

\footnotetext{
* Correspondence: furuzono@waka.kindai.ac.jp

${ }^{1}$ Biological System Engineering, Graduate School of Biology-Oriented Science and Technology, Kindai University, 930 Nishimitani, Kinokawa, Wakayama 649-6493, Japan

Full list of author information is available at the end of the article
}

catheter-related infections. It has also been reported that catheters impregnated with antimicrobial agents reduced PD catheter infections in rats $[4,5]$. However, these types of catheters are not widely available in clinical fields.

Other methods for deterring catheter-related infections that use antibacterial agents, such as chlorhexidineimpregnated dressings which have been proved to be effective in preventing catheter-related infections for intravascular catheters, have not been adequately evaluated for PD treatment [6]. As a countermeasure against infections, an antibacterial catheter impregnated with chlorhexidinesilver sulfadiazine has been used as a central venous catheter. However, the use of the antibacterial catheters in

(C) The Author(s). 2020 Open Access This article is distributed under the terms of the Creative Commons Attribution 4.0 International License (http://creativecommons.org/licenses/by/4.0/), which permits unrestricted use, distribution, and 
Japan have been discontinued due to thirteen cases of serious anaphylactic shock related to the catheters [7].

Considering this information, Furuzono et al. developed a hydroxyapatite (HAp) nanoparticle-coating technology for medical devices aiming to control infection from a catheter [8]. The coating method used the highly dispersible and crystalline HAp nanoparticles showing biocompatibility that led the catheter to close tightly around the exit site of skin. However, since HAp exhibits no antimicrobial property, microorganisms may migrate and proliferate in a living body when the HAp barrier is broken. Therefore, it is necessary to provide HAp with a persistent antibacterial activity without damaging the body.

It is well-known that $\mathrm{F}$ ions are used in additives in toothpastes in oral care [9]. Highly dispersible and crystalline fluorinated HAp (F-HAp) was previously synthesized using an anti-sintering agent [10]. The F-HAp with $90 \%$ of F substitution content possessed weak antibacterial activity against wild-type E. coli. Although the preliminarily report showed effective results, more detailed information is necessary to develop a novel antibacterial-coating material with long-term effectiveness.

In this study, three types of dispersible F-HAp nanoparticles with different $\mathrm{F}$ substitution contents were prepared. The chemical and biological properties of F-HAps, such as chemical stability, antibacterial activity, and release behavior of the $\mathrm{F}$ ions, were evaluated in order to determine its potential as a coating material on a catheter.

\section{Methods}

\section{Materials}

Analytical grade calcium nitrate tetrahydrate $\left[\mathrm{Ca}\left(\mathrm{NO}_{3}\right)_{2}\right.$. $\left.4 \mathrm{H}_{2} \mathrm{O}\right]$, sodium fluoride [NaF], and $85 \%$ phosphoric acid $\left[\mathrm{H}_{3} \mathrm{PO}_{4}\right]$ were purchased by Wako Pure Chemical Industries Ltd. (Osaka, Japan) and were used as synthetic reagents of F-HAp. Polyacrylic acid (PAA, Mw $=6000$ ) for an anti-sintering agent was obtained from Toagosei Co., Ltd. (Tokyo, Japan). Normal HAp was donated from SofSera Co., Ltd., Tokyo, Japan.

\section{Preparation and characterizations of F-HAp}

The preparation of F-HAp nanoparticles was carried out using a wet chemical method. First, $30 \mathrm{mmol}$ of $\mathrm{Ca}\left(\mathrm{NO}_{3}\right)_{2}$. $4 \mathrm{H}_{2} \mathrm{O}$ in $200 \mathrm{~mL}$ anhydrous ethanol and $6.0 \mathrm{mmol} \mathrm{NaF}$ in $200 \mathrm{~mL}$ ethanol were mixed together and stirred at room temperature. Next, $18 \mathrm{mmol}$ of $\mathrm{H}_{3} \mathrm{PO}_{4}$ in $50 \mathrm{~mL}$ ethanol was added to the solution and reacted at $80^{\circ} \mathrm{C}$ in water bath for $1 \mathrm{~h}$. Then, the solution was washed three times with deionized water. F-HAp was mixed in an aqueous solution with PAA and $\mathrm{Ca}\left(\mathrm{NO}_{3}\right)_{2}$ (PAA-Ca) as an antisintering agent for the purpose of improving the dispersibility of the nanoparticles. After this step, the wet cake was calcinated at $800^{\circ} \mathrm{C}$ for $1 \mathrm{~h}$. The products were washed with an ammonium nitrate solution $(1.0 \mathrm{w} / \mathrm{v} \%)$ until the F-
HAp suspension was $\mathrm{pH}$ 7.0. Then, the products were washed three more times with deionized water followed by drying. F-HAps with different F substitution contents were prepared by the same method by adjusting the molar ratio of $\mathrm{NaF}$ from 1.8 to 3.0 mmol. The powder samples were named $F(100)$-HAp, F(50)-HAp, and F(30)-HAp based on their F contents. In addition, normal HAp was used for the control material and was abbreviated into NHAp.

\section{Measurements}

X-ray diffraction (XRD) (MiniFlex, Rigaku Co., Tokyo., Japan) analysis was performed on a RAD-X diffractometer with $\mathrm{Cu} \mathrm{K \alpha}(\lambda=1.5418 \AA)$ to determine the crystalline structure of the samples. The diffraction patterns were collected in the $2 \theta$ range of $10-80^{\circ}$, with a step size of $0.01^{\circ}$. The surface $\zeta$-potential of the F-HAp nanoparticles in $10 \mathrm{mM} \mathrm{KNO}_{3}$ as supporting electrolytes was measured by an electrophoretic light-scattering spectrophotometer (ELS) (ELS-8000 equipped with a flat-plate sample holder; Otsuka Electronics Co., Ltd., Osaka, Japan) at room temperature using a standard polystyrene latex particle with a size of $204 \mathrm{~nm}$ [11]. Fourier-transform infrared spectroscopy (FT-IR) (Spectrum One, Parkin-Elmer Japan Co., Ltd., Yokohama, Japan) measurement was used for sample identification. The measurement was prepared by pressing the powder mixture with $\mathrm{KBr}$, and the spectra were captured in the $400-4000 \mathrm{~cm}^{-1}$ range with 16 scans. The morphologies of nanoparticles were observed using a field emission scanning electron microscope (FE-SEM)(JSM-6301F, JEOL Ltd., Tokyo, Japan) operating at $5 \mathrm{kV}$ with an emission current of $8 \mathrm{~mA}$. The particle sizes were also determined by SEM observation $(n=50)$. F substitution content was determined using a fluoride meter (F10Z) (Kasahara Chemical Instruments Co., Saitama, Japan).

\section{Acid resistance}

The acid resistance of F-HAps was carried out using a UV-Vis spectrometer V-550 (JASCO Co., Tokyo, Japan). The transmittance of $0.04 \mathrm{w} / \mathrm{v} \%$ sample solutions with dispersed F-HAp and NHAp was measured in different $\mathrm{pH}$ phosphate buffer solutions adjusted by $1 \mathrm{M} \mathrm{HCl}$.

\section{Antimicrobial assay}

F-HAp powder was used to evaluate the antimicrobial activity. $P$. aeruginosa PAO1 was cultivated in $3.0 \mathrm{~mL}$ of a Luria-Bertain (LB) liquid medium ( $1 \%$ tryptone, $1 \% \mathrm{NaCl}$, and $0.5 \%$ yeast extract) at $37^{\circ} \mathrm{C}$ for $20 \mathrm{~h}$, and the culture was diluted with $140 \mathrm{mM} \mathrm{NaCl}$ to adjust $\mathrm{OD}_{600}$ to 0.01 , which was expected to $1.0 \times 10^{7}$ cells $/ \mathrm{mL}$. The bacterial suspension with $0.1 \mathrm{~mL}$ was mixed with $0.1 \mathrm{~mL}$ of F-HAps in $140 \mathrm{mM} \mathrm{NaCl}$. The sample suspensions were incubated at room temperature for $2 \mathrm{~h}$ with gentle agitation. After the preparation of a 10 -fold dilution series of $P$. aeruginosa suspensions with $140 \mathrm{mM} \mathrm{NaCl}, 5 \mu \mathrm{L}$ of each sample was 
dropped onto a plate containing a LB agar medium (LB medium with $1.5 \%$ agar). Viable cells grew into colonies after incubation at $37^{\circ} \mathrm{C}$ for $12 \mathrm{~h}$.

Initially, various quantities of $\mathrm{F}(100)$-HAp, $0,25,50$, 75 , and $100 \mathrm{mg}$ were used in the antibacterial assay with $P$. aeruginosa. Then, the antibacterial activities of the four types of $F$ substitution contents of F-HAps, such as F(100)-HAp, F(50)-HAp, F(30)-HAp, and NHAp, were evaluated. In addition, E. aerogenes with clinical isolation, K. pneumonia ATCC 27736 and S. aureus 209P were examined in order to confirm the F-HAp antimicrobial activity against the infectious bacteria [12].

Data resulting from the antibacterial assay were presented as means \pm SD ( $n=3$ or more). Statistical comparisons were performed with the use of a Student's $t$ test. The level of statistical significance was defined as $p$ $<0.05$. This work was fully approved by the Kindai University Bio-safety Committee and was conducted in accordance with the regulations for use of pathogens.

\section{$F$ ions release behavior}

The release behavior of $\mathrm{F}$ ions from the F-HAp nanoparticles was measured by a sustained release evaluation. $50 \mathrm{mg}$ of $\mathrm{F}(100)$-HAp in $100 \mathrm{~mL}$ of PBS were added to a sample tube. Each sample tube was incubated at $37^{\circ} \mathrm{C}$ for 48 weeks. The sample was taken out from the incubator at predetermined periods, and washed with deionized water and dried. Afterwards, the release ratio of $\mathrm{F}$ ions from the F-HAp was determined by measuring $\mathrm{F}$ ion concentration in the suspension samples.

\section{Results}

Material characterizations

Material characterizations of F-HAps were conducted by XRD, FT-IR, and SEM. XRD and FT-IR were used to determine the material crystal structures and molecular structures, respectively. SEM was also used to observe the material morphologies.

Figure 1 shows the XRD profiles of F-HAps calcinated at $800^{\circ} \mathrm{C}$ for $1 \mathrm{~h}$. All peaks in F-HAps with highly crystalline were of HAp structure, and a peak of crystalline impurities of other calcium phosphate was not observed. In Table 1 , the $\mathrm{F}$ substitution contents of $\mathrm{F}(30)$-HAp, F(50)-HAp, and F(100)-HAp were 24,52 , and $84 \%$, respectively. The unit cell parameters of F-HAps and NHAp are also shown in Table 1. The a-axis lengths of F-HAps decreased nearly linearly as the F substitution contents increased, and the c-axis showed an almost constant value.

In FT-IR spectra of F-HAps and NHAp as shown in Fig. 2, the adsorption bands of the samples at around $607 / 570$ and $472 \mathrm{~cm}^{-1}$ indicated the presence of $v_{4}\left(\mathrm{PO}_{4}{ }^{3}\right.$ $\left.{ }^{-}\right)$and $v_{2}\left(\mathrm{PO}_{4}{ }^{3-}\right)$ in the lattice, respectively. The bands at 1470-1420 and $876 \mathrm{~cm}^{-1}$ which were assigned to $v_{3}\left(\mathrm{CO}_{3}{ }^{2-}\right)$ and $v_{2}\left(\mathrm{CO}_{3}{ }^{2-}\right)$. The bands at 3570 and $640-$ $630 \mathrm{~cm}^{-1}$ in the spectra of NHAp (a) and F(30)-HAp (b) was attributed to $v(\mathrm{OH})$ and $\zeta(\mathrm{OH})$, respectively. As the F substitution content of F(50)-HAp (c) and F(100)-HAp (d) increased, the bands diminished and eventually disappeared. For the bands at 3537 and $745 \mathrm{~cm}^{-1}$, OH-F appeared. The spectrum of $\mathrm{F}(30)$-HAp (b) appeared to be more complicated. The bands at 712 and $658 \mathrm{~cm}^{-1}$ exhibited OH-F-HO $[13,14]$. The existence of this adsorption was associated with the appearance of the two bands of $v(\mathrm{OH})$ and $\mathrm{OH}-\mathrm{F}$ at 3570 and $3537 \mathrm{~cm}^{-1}$, respectively, in the spectrum of $\mathrm{F}(30)$-HAp (b).

\section{SEM observation}

The SEM image of F-HAp is shown in Fig. 3. The particles of F-HAps powders were dispersed with slight

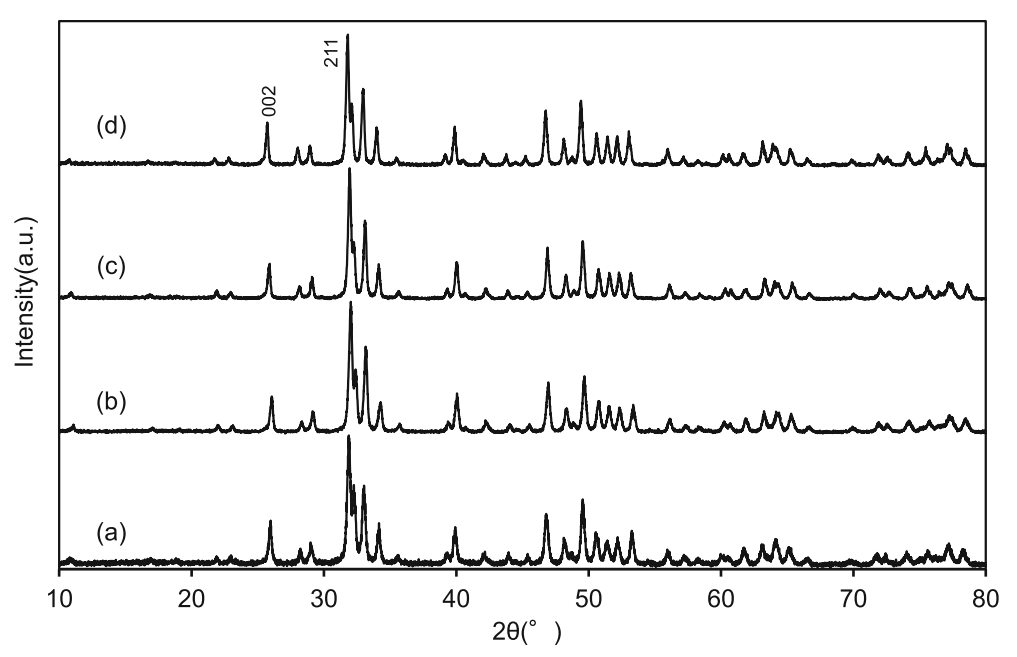

Fig. 1 XRD profiles of a NHAp, b F(30)-HAp, c F(50)-HAp, and $\mathbf{d} F(100)-H A p$ 
Table 1 Fluoride ion content, unit cell parameters, and Z-potential of F-HAp and HAp

\begin{tabular}{|c|c|c|c|c|c|}
\hline \multirow[t]{2}{*}{ Sample } & \multicolumn{2}{|c|}{ Fluoride ion content (\%) ** } & \multicolumn{2}{|c|}{ Unit cell parameters } & \multirow{2}{*}{$\begin{array}{l}\zeta- \\
\text { potential } \\
(\mathrm{mV})\end{array}$} \\
\hline & Feed & Measured & $\overline{\text { a-axis }(\AA)}$ & c-axis $(\AA)$ & \\
\hline NHAp* & 0 & 0 & 9.439 & 6.895 & 1.43 \\
\hline$F(30)-H A p$ & 30 & 24 & 9.431 & 6.886 & -0.32 \\
\hline$F(50)-H A p$ & 50 & 52 & 9.407 & 6.905 & -1.63 \\
\hline$F(100)-H A p$ & 100 & 84 & 9.382 & 6.892 & -21.1 \\
\hline
\end{tabular}

*NHAp refers to normal hydroxyapatite

**Fluoride ion content $(\%)$ shows $[\mathrm{F} /(\mathrm{F}+\mathrm{OH}) \times 100]$ in $\mathrm{Ca}_{10}\left(\mathrm{PO}_{4}\right)_{6} \mathrm{OH}_{2-\mathrm{x}} \mathrm{F}_{\mathrm{x}}$

agglomerates. The average lengths of the long and short axes of the primary particles in the samples of $\mathrm{F}(30)$ HAp, F(50)-HAp and F(100)-HAp were $216 \pm 98 \mathrm{~nm} /$ $150 \pm 32 \mathrm{~nm}, 519 \pm 310 \mathrm{~nm} / 216 \pm 51 \mathrm{~nm}$ and $810 \pm 275$ $\mathrm{nm} / 255 \pm 50 \mathrm{~nm}$, respectively, as determined by SEM images.

\section{Acid resistance}

The acid resistance test of F-HAps was performed by visible spectrometric turbidity in different acidic solution conditions from pH 5.0 to 2.0 (Fig. 4). Low values of light transmittance indicate an insoluble state of a powder solution, while high values indicate a soluble state. The initial soluble points of F-HAps decreased as F substitution contents increased.

\section{Antibacterial effect}

In the antibacterial test, Fig. 5 and Additional file 1: Figure S1 show the survival ratios and antibacterial effect against $P$. aeruginosa for F-HAps and NHAp. While NHAp powders used as the negative control showed no antibacterial activity, the cell survival ratios of F-HAps were significantly lower than that of NHAp. The ratio of $\mathrm{F}(100)$-HAp was, moreover, the lowest of all sample powders. Fifty to sixty percent of the antimicrobial activities of $\mathrm{F}(100)$-HAp indicated against the other three types of causative bacteria of catheter-related infection, such as $S$. aureus, E. aerogenes, and K. pneumoniae as shown in Fig. 6.

\section{$\mathrm{F}$ ions release behavior}

The F ions release behavior of F(100)-HAp was investigated for 48 weeks. F ions were gradually and continuously released and finally plateaued at 24 weeks as shown in Fig. 7.

\section{Discussion}

F-HAps were prepared using an anti-sintering agent in order to prevent agglomerates during calcination. From these results of XRD and F ion content measurements as shown in Fig. 1 and Table 1, it was confirmed that the $\mathrm{OH}$ groups were replaced from 80 to $100 \%$ with $\mathrm{F}$ ions in the F-HAp preparation. This was because $\mathrm{F}$ ions were adequately substituted in HAp structures in an anhydrous synthesis system. The a- and c-axis values trends were in agreement with former reports $[13,15]$. The phenomenon was dependent on the $\mathrm{F}$ ion radius $(1.32 \AA)$ being smaller than that of the $\mathrm{OH}$ group (1.68 $\AA$ ) [16].

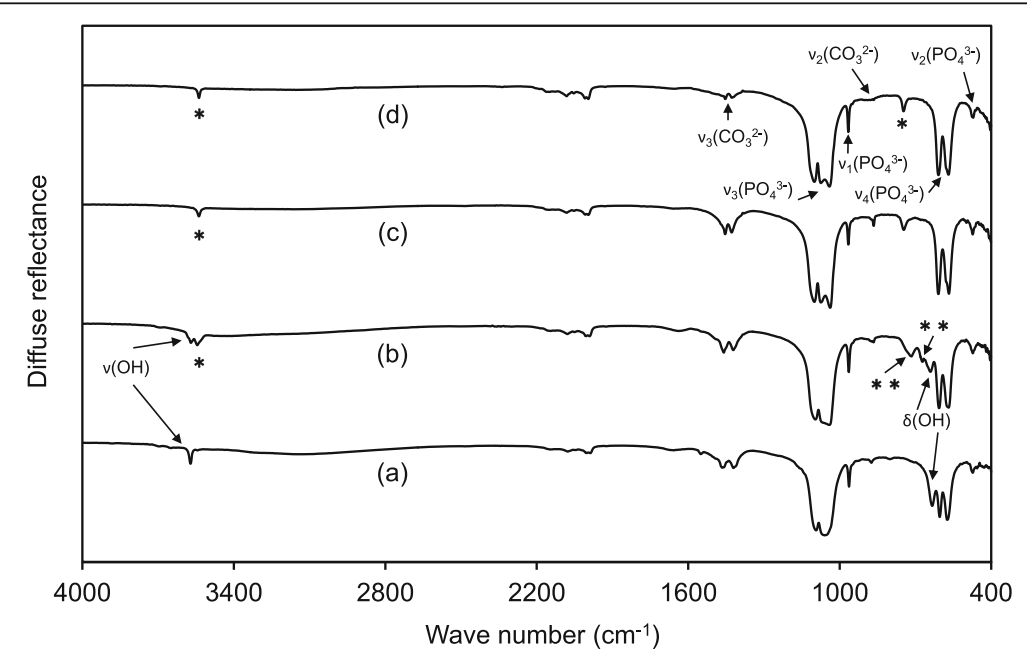

Fig. 2 FT-IR spectra of a NHAp, b F(30)-HAp, c F(50)-HAp, and d F(100)-HAp* OH-F, ** OH-F-OH 

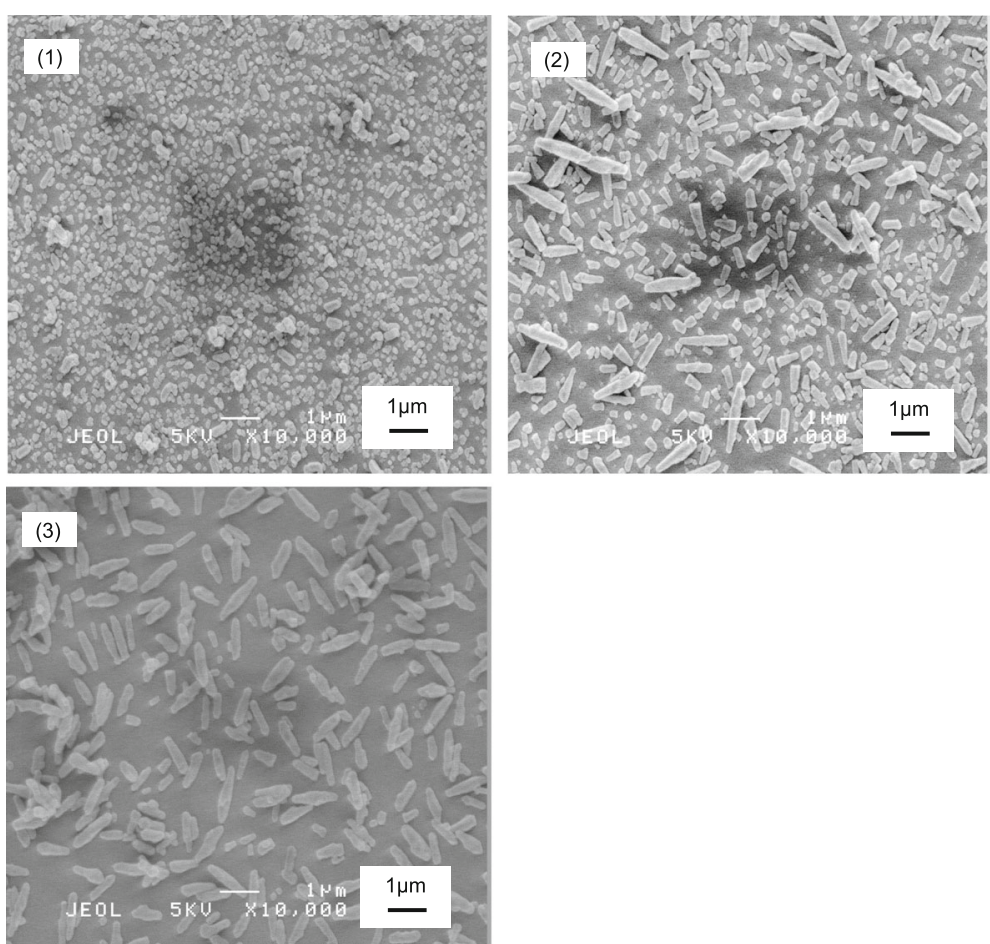

Fig. 3 SEM images of $\mathbf{1} F(30)-H A p, 2$ F(50)-HAp, and $\mathbf{3} F(100)$-HAp nanoparticles $(\times 10,000)$

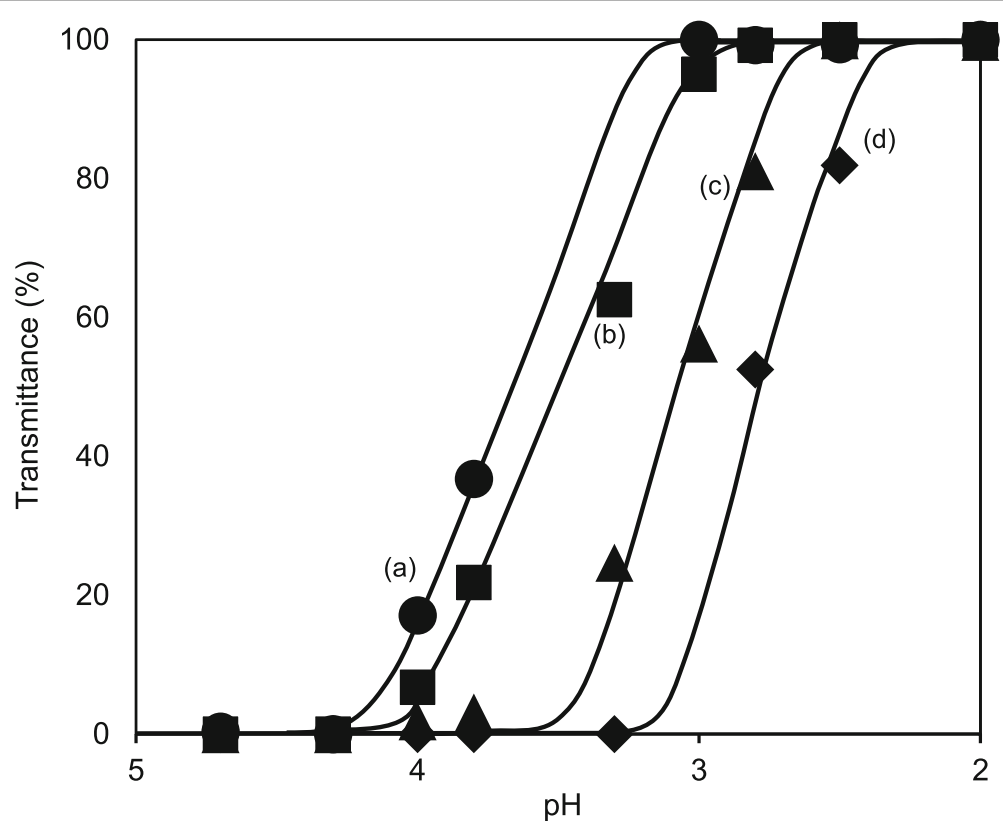

Fig. 4 Acid resistance curves of F-HAp and HAp powders. The solid lines of closed circles a NHAp, the closed squares $\mathbf{b}$ F(30)-HAp, the closed triangles $\mathbf{c}$ F(50)-HAp and the closed diamonds $\mathbf{d}$ F(100)-HAp show solubilities of F-HAp in different pH solutions 


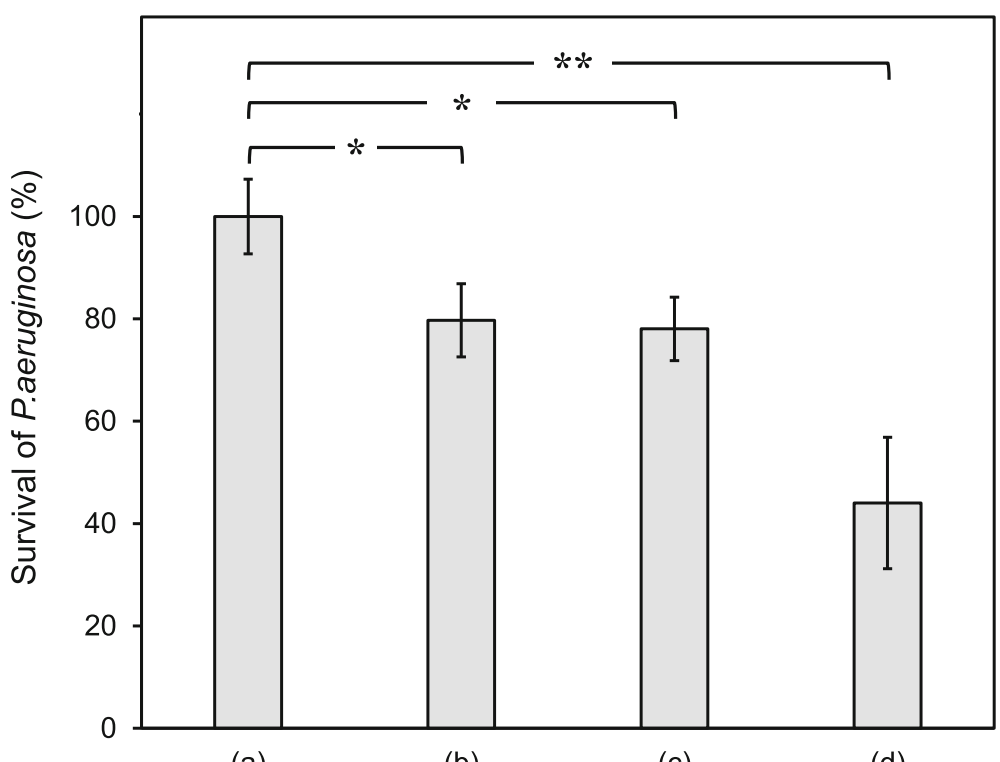

(a)

(b)

(c)

(d)

Sample powder

Fig. 5 Survival ratio of $P$. aeruginosa in contact with each sample powder (50 mg/0.2 mL) of a NHAp, b F(30)-HAp, c F(50)-HAp, and d F(100)-HAp. Error bars show $\pm \operatorname{SD}(n=4)$, and single and double asterisks mean $p<0.05$ and $p<0.01$, respectively, by unpaired Student's $t$ test

In the FT-IR measurements, the carbonate ions in the F-HAp structure were derived from the decomposition of the PAA anti-sintering agent, indicated a biological Btype of carbonate apatite [14, 17]. The interaction between $\mathrm{F}$ ions and $\mathrm{OH}$ groups may imply the existence of random interactions between partially substituted $\mathrm{F}$ ions and $\mathrm{OH}$ groups in the HAp crystalline structure.

From the SEM observations, the particle sizes of F-HAp increased with increasing of $\mathrm{F}$ substitution of content. Nathanael et al. reported that the tendency of the crystalline growth of F-HAp particles depends on the increase of the crystallinity [18]. However, the crystallinities of the FHAps in this study were almost the same as shown in Fig. 1. Therefore, further study of the crystalline growth of FHAp with increasing F substitution content is necessary.
The material stability was evaluated by the acid resistance test. Okazaki et al. found that the solubility of fluorinated carbonate apatite at $\mathrm{pH} 4.0$ in an acetate buffer solution decreased with an increase in the degree of fluoridation [19]. The solubility behavior coincided with our result. The chemical stability of F-HAps in acidic conditions depended on the strong interactions between $\mathrm{F}$ ions and $\mathrm{H}$ ions of $\mathrm{OH}$ groups in the crystalline structure [20].

For the first antibacterial test, $P$. aeruginosa as a causative bacterium of catheter-related infections was used in order to determine the optimal adding amount of $\mathrm{F}(100)$ HAp powder. The lethal dose $50\left(\mathrm{LD}_{50}\right)$ of $\mathrm{F}(100)$-HAp powder was observed at approximately $50 \mathrm{mg}$ in $0.2 \mathrm{~mL}$ of $\mathrm{NaCl}$ aqueous solution as shown in Additional file 1:

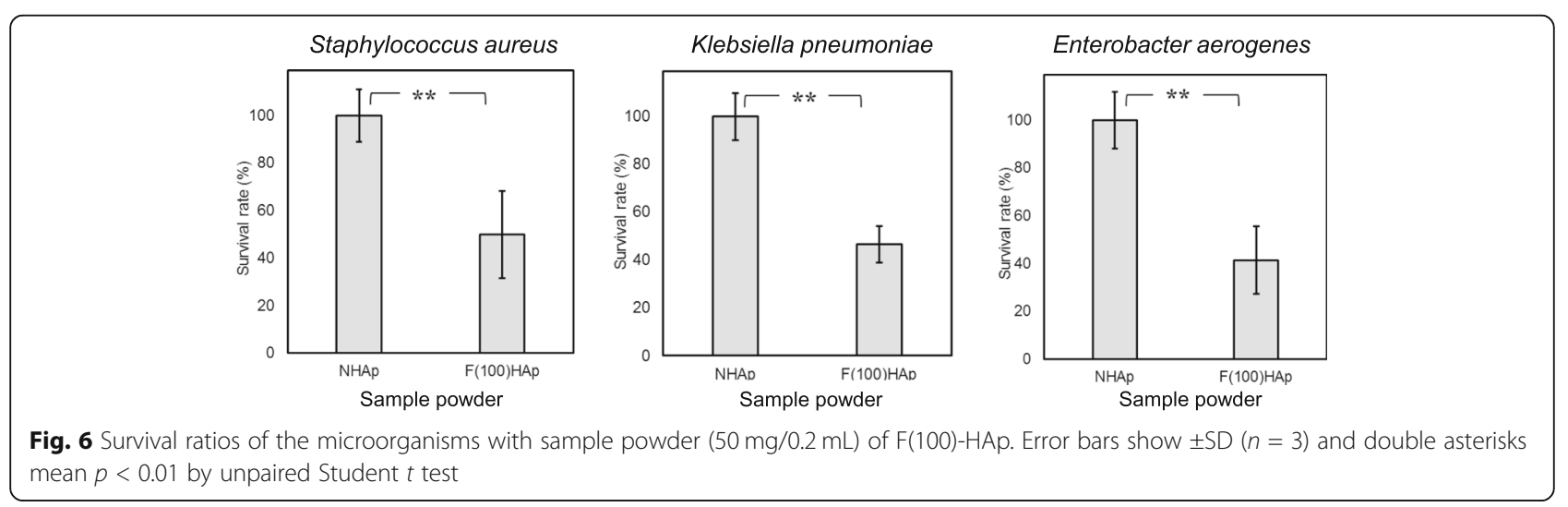




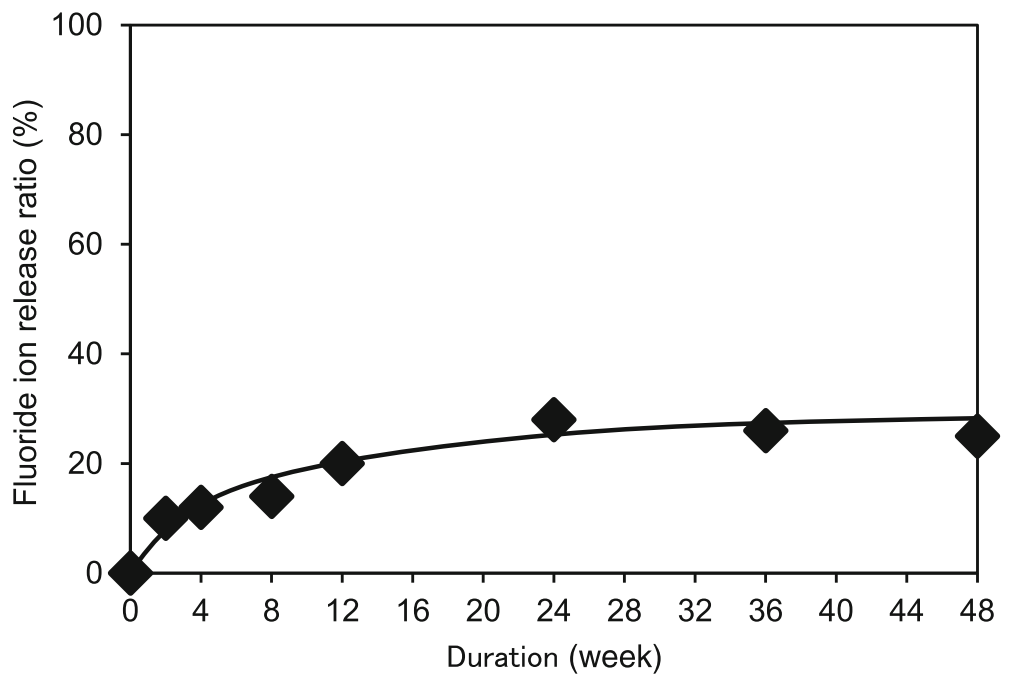

Fig. 7 Fluoride ion release ratio from $\mathrm{F}(100)-\mathrm{HAp}$ nanoparticles in $\mathrm{PBS}$ at $37^{\circ} \mathrm{C}$.

Figure S2. Based on this result, the concentration of all F-HAps for the following tests of antibacterial activity was determined at $50 \mathrm{mg} / 0.2 \mathrm{~mL}$.

It was clear that the sterilization rate of F-HAp depended on the F substitution content in Fig. 5. Based on the result in the antibacterial assay against the other three types of causative bacteria of catheter-related infections, such as $S$. aureus, E. aerogenes, and K. pneumoniae, it was also suggested that $\mathrm{F}$ ions contributed to the antibacterial activity of F-HAp as shown in Fig. 6. It is well-known that $\mathrm{F}$ ions inhibit enolase and subsequently suppress the production of pyruvic acid in glycolysis systems [16, 21, 22]. As the mechanism for the antimicrobial effects of F-HAp, $F$ ions released from the nanoparticles were assumed to come in contact with or migrate into bacterium membranes, prohibit enolase activity in the cytoplasm, and damage cell growth. Especially, S. aureus is known as the most common pathogen of PD catheter-related infections [23]. The detailed examinations regarding $S$. aureus, such as quantitative experiments and the mechanism of action, is planned for an advanced research.

The $\mathrm{F}$ ions release behavior of $\mathrm{F}(100)$-HAp may be explained by the $\zeta$-potential value as shown in Fig. 7 and Table 1 . The $\zeta$-potential value of F-HAps decreased as increasing with $\mathrm{F}$ substitution content, and the value of F(100)-HAp showed much lower than that of other FHAps. It was thought that a layer with high $\mathrm{F}$ ion content might exist in the outermost surface of a $F(100)$-HAp nanoparticle, whereas the actual $\mathrm{F}$ ion content of the bulk samples was $84 \%$. In addition, the nanoparticles showed high dispersibility. It was thought that the outermost layer containing $F$ ions in $F(100)$-HAp nanoparticles might initially gradually dissolved in the aqueous solution. $\mathrm{F}$ ions attributed to the crystalline layer of the nanoparticle seemed to be slowly released until 24 weeks.
Schierholz et al. reported that the half-life antibacterial activity of a central venous catheter coated with miconazole and rifampicin exceeded 3 weeks in vitro [24]. In contrast, $\mathrm{F}(100)$-HAp potentially held the antibacterial activity for 24 weeks. The difference in release behavior between such an antibiotic coating and our F-HAp nanoparticles depended on substantial in vivo stability. Therefore, the nanoparticles might be useful as an antibacterial coating material for a long-term indwelling catheter.

The findings of encapsulating peritoneal sclerosis have decreased by using a neutral PD solution in Japan [25]. Occasionally, PD treatment is prolonged for a decade due to the sustainment of residual kidney function. Although the retention possibility of the antibacterial effect of $F(100)$ HAp was about 24 weeks, the period of the effectiveness is still unsatisfactory for PD catheters. However, the antibacterial effectiveness can potentially be prolonged by the precise control of crystallinity, chemical stability, coating density and multi-layer coating of F-HAp nanoparticles.

\section{Conclusions}

Highly dispersible and crystalline fluorinated hydroxyapatite nanoparticles were prepared by a wet chemical processing using an anti-sintering agent. F-HAps were substituted with $\mathrm{F}$ ions to different degrees. The acid resistance, i.e., chemical stability, of F-HAps increased with increasing of $\mathrm{F}$ substitution content. The antibacterial effect of F-HAps suggests the possibility of controlling the sterilization rate by varying the $\mathrm{F}$ ion content. The potential retention period of the antibacterial effect of $F(100)$-HAp was for 24 weeks. While the duration of the antibacterial effect has not yet satisfied the requirements for PD catheters, it is expected that the performance might be improved by more precise control using of material engineering technology. 


\section{Supplementary information}

Supplementary information accompanies this paper at https://doi.org/10. 1186/s41100-019-0251-6

Additional file 1: Figure S1. The antibacterial effects of F-HAp against $P$. aeruginosa using the agar spot method. This figure corresponds to experimental repetition 1 out of $n=4$ in Fig. 5. Figure S2. Survival ratio of $P$. aeruginosa in contact with $F(100)$-HAp powder $(0-100 \mathrm{mg} / 0.2 \mathrm{~mL})$.

\section{Abbreviations}

ELS: Electrophoretic light-scattering spectrophotometer; ESI: Exit-site infection; F-HAp: Fluorine-substituted hydroxyapatite; FT-IR: Fourier-transform infrared spectroscopy; HAp: Hydroxyapatite; LB: Luria-Bertain; PAA: Polyacrylic acid; PD: Peritoneal dialysis; SEM: Scanning electron microscope; XRD: X-rays diffraction

\section{Acknowledgements}

The authors would like to thank Mr. Ohyabu T, Kindai University, for his assistance in the experiments, and Dr. Kogai Y. and Dr. Uemukai T., SofSera Co., for their technical supports. The authors also thank the committee for new technologies to blood purification therapy, JSDT for kindly discussion.

\section{Authors' contributions}

$\mathrm{GH}$ and $\mathrm{FT}$ were involved in the implementation, data analysis, and article writing related to the study. AY evaluated the antimicrobial test results. All authors read and approved the final manuscript.

\section{Funding}

The study was supported in part by a JSPS Grant-in-Aid for Scientific Research (C) (KAKENHI), grant number 16 K01401.

\section{Availability of data and materials}

The datasets used and analyzed during the current study are available upon corresponding request to the corresponding author.

\section{Ethics approval and consent to participate}

The antibacterial assay was fully approved by the Kindai University Biosafety Committee and the study was conducted in accordance with the regulations for use of recombinant pathogens.

\section{Consent for publication}

Not applicable.

\section{Competing interests}

Furuzono T. serves as a consultant to SofSera Corporation.

\section{Author details}

${ }^{1}$ Biological System Engineering, Graduate School of Biology-Oriented Science and Technology, Kindai University, 930 Nishimitani, Kinokawa, Wakayama 649-6493, Japan. Biotechnological Science, Graduate School of Biology-Oriented Science and Technology, Kindai University, 930 Nishimitani, Kinokawa, Wakayama 649-6493, Japan.

Received: 25 September 2019 Accepted: 17 December 2019 Published online: 08 January 2020

\section{References}

1. Li PK, Szeto CC, Piraino B, Arteaga J, Fan S, Figueiredo AE, Fish DN, Goffin E, Kim Y, Salzer W, Struijk DG, Teitelbaum I, Johnson DW. ISPD Peritonitis recommendations: 2016 update on prevention and treatment. Perit Dial Int. 2016;36:481-508.

2. Szeto CC, Li PK, Johnson DW, Bernardini J, Dong J, Figueiredo AE, Ito $Y$, Kazancioglu R, Moraes T, Esch SV, Brown EA. ISPD Catheter-related infection recommendations: 2017 update. Perit Dial Int. 2017;37:141-54.

3. van Diepen AT, Tomlinson GA, Jassal SV. The association between exit site infection and subsequent peritonitis among peritoneal dialysis patients. Clin J Am Soc Nephrol. 2012;7:1266-71.

4. Crabtree JH, Burchette RJ, Siddiqi RA, Huen IT, Hadnott LL, Fishman A. The efficacy of silver-ion implanted catheters in reducing peritoneal dialysisrelated infections. Perit Dial Int. 2003;23:368-74.
5. Tobin EJ, Bambauer R. Silver coating of dialysis catheters to reduce bacterial colonization and infection. Ther Apher Dial. 2003;7:504-9.

6. Timsit JF, Schwebel C, Bouadma L, Geffroy A, Garrouste-Orgeas M, Pease S, Herault MC, Haouache H, Calvino-Gunther S, Gestin B, Armand-Lefevre L, Leflon V, Chaplain C, Benali A, Francais A, Adrie C, Zahar JR, Thuong M, Arrault X, Croize J, Lucet JC, Dressing Study Group. Chlorhexidineimpregnated sponges and less frequent dressing changes for prevention of catheter-related infections in critically ill adults: a randomized controlled trial. JAMA. 2009:301:1231-41.

7. David LV, Sanjay S, Sean DS. Cost-effectiveness of antiseptic-impregnated central venous catheters for the prevention of catheter-related bloodstream infection. JAMA. 1999;282:554-60

8. Furuzono T, Ueki M, Kitamura H, Oka K, Imai E. Histological reaction of sintered nanohydroxyapatite-coated cuff and its fibroblast-like cell hybrid for an indwelling catheter. J Biomed Mater Res B Appl Biomater. 2009;89:77-85.

9. Bibby BG, De Roche E, Wilkins E. The effect of topical applications of lead fluoride on dental caries. J Dent Res. 1947;26:446.

10. Furuzono T, Azuma Y, Nigawa Y, Kogai Y, Sawa Y. Preparation and characterization of dispersible fluorinated hydroxyapatite nanoparticles with weak antibacterial activity. ASAIO J. 2016;62:197-202.

11. Okada M, Furukawa K, Serikawa T, Yanagisawa Y, Tanaka H, Kawai T, Furuzono T. Interfacial interactions between calcined hydroxyapatite nanocrystals and substrates. Langmuir. 2009;25:6300-6.

12. Yamashita E, Morikane $K$, Taniguchi H, Miyata T, Maeta K, Takahashi Y, Osawa T, Hosoda K, Murata H, Ito J, Matayoshi K, Obikane S, Tago Y, Hayashinuma S, Mizono S, Oku Y, Tsubone Y, Hatakeyama K, Yoshikawa M, Masamoto M, Kamiya M, Nakashima H. Characteristics of vascular access-associated infection and reduction through surveillance. Jpn J Infect Control. 2016;31:297-309.

13. Rodriguez-Lorenzo LM, Hart JN, Gross KA. Influence of fluorine in the synthesis of apatites: Synthesis of solid solutions of hydroxy-fluorapatite. Biomaterials. 2003;24:3777-85.

14. Rameshbabu N, Kumar TSS, Rao KP. Synthesis of nanocrystalline fluorinated hydroxyapatite by microwave processing and its vitro dissolution study. Bull Mater Sci. 2006;29:611-5

15. Rintoul L, Wentrruo-Byrne E, Suzuki S, Grøndahl L. FT-IR spectroscopy of fluoro-substituted hydroxyapatite: strengths and limitations. J Mater Sci Mater Med. 2007:18:1701-9.

16. Narasaraji TSB, Phebe DE. Some physic-chmical aspects of hydroxyapatite. J Mater Sci. 1996;31:1-21.

17. Stanic V, Dimitijevic S, Antonovic DG, Jokic BM, Zec SP, Tanaskovic ST, Raicevic S. Synthesis of fluorine substituted hydroxyapatite nanopowders and application of the central composite design for determination of its antimicrobial effects. Appl Surf Sci. 2014;290:346-52.

18. Nathanael AJ, Mangalaraj D, Hong SI, Masuda Y, Rhee YH, Kim HW. Influence of fluorine substitution on the morphology and structure of hydroxyapatite nanocrtstals prepared by hydrothermal method. Mater Chem Phys. 2013;137:967-76.

19. Okazaki M, Takahashi J, Kimura H, Aoba T. Crystallinity, solubility, and dissolution rate behavior of fluoridated $\mathrm{CO}_{3}$ apatites. J Biomed Mater Res. 1982;16:851-60.

20. Chen $Y$, Miao X. Thermal and chemical stability of fluorohydroxyapatite ceramics with different fluorine contents. Biomaterials. 2005;26:1205-10.

21. Marquis RE, Clock SA, Mota-Meira M. Fluoride and organic weak acids as modulators of microbial physiology. FEMS Microbiol Rev. 2003;26:493-510.

22. Kaufmann M, Bartholmes P. Purification, Characterization and inhibition by fluoride of enolase from Streptococcus mutans DSM 320523. Caries Res. 1992;26:110-6.

23. Nodaira Y, Ikeda N, Kobayashi K, Watanabe Y, Inoue T, Gen S, Kanno Y, Nakamoto H, Suzuki H. Risk factors and cause of removal of peritoneal dialysis catheter in patients on continuous ambulatory peritoneal dialysis. Adv Perit Dial. 2008;24:65-8.

24. Schierholz JM, Fleck C, Beuth J, Pulverer G. The antibacterial efficacy of a new central venous catheter with long-term broad-spectrum activity. J Antimicrob Chemother. 2000:46:45-50.

25. Nakayama M, Miyazaki M, Honda K, Kasai K, Tomo T, Nakamoto H, Kawanishi $H$. Encapsulating peritoneal sclerosis in the era of a multi-disciplinary approach based on biocompatible solutions: the NEXT-PD study. Perit Dial Int. 2014;34:766-74.

\section{Publisher's Note}

Springer Nature remains neutral with regard to jurisdictional claims in published maps and institutional affiliations. 